CONFERENCIAS E DISCURSOS.

$$
\begin{aligned}
& 347.97: 342(430) \\
& 351.713(430)
\end{aligned}
$$

\title{
La influencia de la jurisprudencia del Tribunal Constitucional Federal sobre el Derecho Fiscal de la República Federal de Alemania*.
}

\author{
Klaus Vogel \\ Cateđrático de Direito Pablico, especializado \\ em Direito Administrativo e Tributário, do \\ Institut für Deutsches und Internationales \\ Steuprecht der Universitat Heildelberg.
}

I.

En una conferencia de cuarenta o cuarenta y cinco minutos no es posible exponer - ni siquiera limitandose a las generalidades - todo el Derecho fiscal de un Estado; la exposición habria de ser necesariamente demasiado superficial y su resultado, por ello, demasiado insatisfactorio. Habría de limitarse a mostrar algunas de sus líneas fundamentales, pero sucede que en estas lineas generales el Derecho Fiscal alemán coincide en buena medida con el de otros muchos Estados; por el contrario, seria obligado descuidar lo que constituye lo específico y peculiar del Derecho fiscal alemán ( $\mathrm{y}$ que por ello seria posiblemente de mucho mayor interes para ustedes).

Por este motivo quisiera proceder de forma inversa, informandoles a ustedes sobre algunas importantes resoluciones de nuestros más altos Tribunales en materia de Derecho fiscal, resoluciones que he seleccionado de manera

* Conferência proferida em 21 de outubro de 1968, na cadeira de Direito Tributário do Cur'so de Especialização da Faculdade de Direito da usp, de que é titular o Prof. RuY Barbosa Nogueira. 
que, al mismo tiempo, $-\mathrm{y}$ así lo espero puedan proporcionarles a ustedes una idea de nuestras mas importantes leyes tributarias. Todas las resoluciones seleccionadas tienen un tema comun: el influjo que en nuestro país ha ejercido y sigue todavia hoy ejerciendo el Derecho Constitucional sobre la evolucion del Derecho Fiscal. Pues aqui me parece que radica una importante peculiaridad de nuestro Derecho Fiscal que puede ser también de interés para ustedes: por lo que yo conozco, no hay ningún otro país del mundo en el cual la legislación tributaria haya sido tan intensa y duraderamente influida por el Derecho constitucional como en la República Federal de Alemania durante los dos últimos decenios.

Cómo ha llegado a ser ello posible? Nuestra Constitución, la "Ley Fundamental" de veintitres de Mayo de mil novecientos cuarenta y nueve, se considera a si misma como una ordenación jerarquicamente superior a todos los demás actos de soberanía, incluidas también las leyes. Ustedes saben muy bien que esta no es una interpretación generalmente aceptada y que hay muchos Estados en los cuales toda ley aprobada por el Parlamento, también la ley anticonstitucional, tiene que ser respetada por todos os demás órganos del Estado. En estos Estados por consiguiente, la Constitución es en realidad para el Parlamento más bien una "norma orientadora", en ningún caso una lex perfecta cuya violación trajera consigo la invalidez de la ley anticonstitucional. En la República Federal de Alemania, por el contrario, debido a determinados acontecimientos de sua historia, se considera actualmente la Constitución como una norma sbolutamente vinculante $\mathrm{y}$ nula toda ley que atente contra ella.

Competente para declarar la anticonstitucionalidad de una ley es el Tribunal Constitucional Federal, uno de los Altos órganos Federales, que funciona con autonomia e independencia al lado del Parlamento y del Gobierno federal. Para someter al Tribunal Constitucional Federal la cuestión de la constitucionalidad de una ley pueden 
seguirse distintos procedimientos: determinados órganos del Estado tienen el derecho de acudir al Tribunal Constitucional solicitandole que someta a estudio una ley; tiene ademas esta facultad todo Tribunal que considere anticonstitucional una ley sobre la que habria de fundamentarse una determinada y concreta resolución; y finalmente cualquier ciudadano singular puede acudir al Tribunal Constitucional Federal si una ley anticonstitucional lesiona uno de sus derechos fundamentales. En mi conferencia sobre la "tutela jurídica frente al poder público" les he informado más detenidamente sobre esta posibilidad (les informaré algo más detenidamente sobre esta posibilidad). Cuando el Tribunal Constitucional declara en su resolución la anticonstitucionalidad de una ley, se considera esta nula desde el primer momento - por razones derivadas de la tradición constitucional alemana -; que ello no deja de plantear problemas, tendremos ocasión de comprobarlo más adelante.

Como criterios que sirven de pauta para el control de la constitucionalidad de las leyes entran especialmente en consideración los derechos fundamentales del ciudadano consignados en los articulos uno e diecinueve de la Ley Fundamental; en relación con el Derecho fiscal ha adquirido sobre todo relevancia el principio de igualdad formulado en el articulo tercero. De las restantes disposiciones de la Ley Fundamental quisiera mencionar ademas especialmente el articulo ochenta: a tenor de esta disposición toda autorización legal al ejecutivo para dictar un decreto o un reglamento ha de ser precisada de tal manera, ya en la misma ley, que pueda preverse el contenido y el alcance de los mismos; con ello se quiere impedir que el Parlamento lleve a cabo una delegación demasiado amplia de sus facultades legislativas. A estas disposiciones especiales de la Ley Fundamental vienen a anadirse finalmente, como criterios a que ha de atenerse la legislación, algunos principios constitucionales de orden general proclamados por la Ley Fundamental en su Artículo veinte y que 
definen a la República Federal de Alemania como un Estado de Derecho, social y democrático. Partiendo de estos principios constitucionales generales y desarrollándolos creadoramente el Tribunal Constitucional ha deducido algunos otros postulados a los que debe ajustarse la actuación del legislador y del ejecutivo: así por ejemplo, la prohibición absoluta general de toda forma de retroactividad de las leyes impositivas.

Desde el año mil novecientos cincuenta y uno en que comenzo su actividad el Tribunal Constitucional Federal ha tenido que juzgar, ajustandose a estos criterios, sobre questiones de Derecho tributario en ya más de setenta casos. En todas las sentencias dictadas ha tomado muy en serio la fuerza vinculante de la Constitución: en toda una seria de casos ha declarado anticonstitucionales las disposiciones de las leyes tributarias y anulado resoluciones de los Tribunales de Hacienda. A continuación quisiera presentarles a ustedes algunos ejemplos de esta jurisprudencia, así como también un fallo de nuestro Tribunal Supremo Federal de Hacienda en el cual se hace también patente el influjo del Derecho Constitucional sobre el Derecho tributario.

$$
\text { II. }
$$

La primera cuestión importante de Derecho Constitucional de que hubo de ocuparse el Tribunal Constitucional Federal en el sector del Derecho Fiscal procedía del campo del impuesto a los réditos (Einkommensteuer). La República Federal grava a todas las personas naturales con un impuesto a los réditos de carácter progressivo - el tipo de gravamen varía entre un diecinueve y un cincuenta y tres por ciento -; en cambio los réditos de las personas jurídicas están sujetos a un impuesto proporcional, el impuesto a las entidades (Korperschaftsteuer) - cuyo tipo asciende por lo regular a un cincuenta y uno por ciento - Todas las personas naturales $\mathrm{y}$ jurídicas son 
gravadas además con un impuesto proporcional que se rige por el monto de su capital; el tipo de gravamen de este impuesto asciende al uno por ciento.

Hasta todavia hace pocos años el Derecho Fiscal alemán, tanto en el caso del impuesto a los réditos como en el del impuesto al capital, partia del principio de la "unidad de la familia". Ello obedecia sobre todo a razones históricas: como ustedes saben en épocas pasadas la familia constituía una unidad mucho más vigorosa que hoy, también en lo que se refiere a la actividad económica: el cabeza de familia, el pater familias, tenía a su cargo la administración y aprovechamiento de todo el patrimonio familiar. A pesar 'de que, como es natural, esta situación cambió hace mucho tiempo en Alemania, hasta hace, poco se tomaba como base para calcular el impuesto a los réditos y al capital la suma global de todos los réditos obtenidos por los miembros de una familia y la totalidad del capital perteneciente a los mismos, respectivamente. De esta manera en el caso de los cónyuges se sumaban los ingresos anuales de ambos y el importe de esta suma servía de base para calcular el gravamen. Esta reglamenlación era especialmente gravosa para los cónyuges porque, como ya decia anteriormente, el tipo del impuesto a los réditos es progresivo. Por esta razón, si ambos cónyuges tenían ingresos propios resultaba que, debido a esta liquidación global, quedaban sujetos a un tipo de gravamen mucho más elevado que si la liquidación se hubiera hecho por separado; es decir, tenían que pagar más impuestos que los contribuyentes solteros con los mismos ingresos anuales. Dado lo acentuado de la progresión - ya hemos dicho que el tipo impositivo oscila entre un diecinueve y un cincuenta y tres por ciento - esta desventaja era tan considerable que en no poces casos los cónyuges habían actuado en consecuencia, divorciando-se para seguir viviendo en "concubinato" y sujetos a un impuesto más bajo.

Ahora bien, el Artículo sexto de nuestra Ley Fundamental coloca expresamente el matrimonio y la familia - 
cito textualmente - "bajo la particular protección del orden estatal". Era en realidad obvio que una legislación de Hacienda que gravaba especialmente el matrimonio, llegando hasta a alentar el divorcio no podia ser compatible con esta disposición constitucional. A pesar de ello siguió vigente dicha reglamentación aun después de la entrada en vigor de la Ley Fundamental; puede que ello se debiera en primera línea a que tanto el Parlamento como el Gobierno no apreciaron entonces en todo su alcance la amplia significación que la Ley Fundamental tenía también para el Derecho Fiscal. Después se hicieron algunos intentos para encontrar razones que justificaran la liquidación conjunta del hogar común supone ahorros para los cónyuges; por consiguiente, los casados están en mejores condiciones que los solteros para soportar las cargas fiscales y por ello pueden ser gravados em mayor medida. Además, si no se gravara con impuestos más elevados a aquellos matrimonios en los cuales ambos cónyuges tienen ingresos, se colocaria en situación desventajosa a aquellos matrimonios en los cuales la esposa no tuviera un empleo retribuido. Al argumentar de esta manera olvidaba el ministro que la ventaja económica que se deriva de la vida em común se da no solo cuando se trata de casados, sino también en cualquiera otra forma de comunidad de vida y sin embargo nadie pensaba en gravar con un impuesto más elevado a los réditos de tales comunidades irregulares de vida.

Por todo ello la argumentación del ministro de Hacienda no era convincente y el Tribunal Constitucional no se adhirió a ella. En su sentencia argumenta el Tribunal que el Artículo sexto de la Ley Fundamental coloca el matrimonio y la familia bajo la particular protección del orden estatal; con arreglo a ello le está vedado al Estado perjudicar o menoscabar de qualquier otra manera el matrimonio. La liquidación global del impuesto a los réditos de los cónyuges representa un menoscabo de esta naturaleza. Por esta razón fue declarado nulo el corres- 
pondiente precepto de la Ley que regula el impuesto a los réditos y la Federación y los Estados federados tuvieron que reembolsar los impuestos indebidamente recaudados, los cuales ascendían a varios millones de marcos alemanes.

En la actualidad el legislador ha pasado a aplicar a los cónyuges el método del llamado "Splitting". Con arreglo al mismo se suman también los réditos de ambos cónyuges, pero luego cada uno de ellos satisface solamente los impuestos correspondientes a la mitad de los ingresos totales. De este modo se evitan las desventajas de orden fiscal que se derivaban de la progresión. Aún más, el método "Splitting" concede un trato de preferencia a aquellos matrimonios en los cuales só lo uno de los cónyuges percibe ingresos; con este método quedan sujetos a un tipo impositivo sustancialmente inferior al que seria aplicable si se hiciera por separado la liquidación del impuesto para ambos cónyuges. Dos cónyuges pueden sin embargo, si lo desean, elegir una liquidación completamente separada, lo cual tendría sus ventajas, sobre todo, cuando ambos perciben una suma de ingresos aproximadamente igual y uno de ellos quisiéra evitar que se le obligara a responder por los impuestos del otro.

Siete años más tarde, em mil novecientos sesenta y cuatro, el Tribunal tuvo que resolver en un caso semejante. Esta vez se trataba de la liquidación global del impuesto a los réditos de padres e hijos, forma prevista también por la ley. El Tribunal Constitucional Federal volvió a apoyarse en el Artículo sexto de la Ley Fundamental que protegé no solo el matrimonio sino la familia en general. También en el caso de padres e hijos la liquidación global suponía, como consecuencia de la progresión, un aumento del gravamen incompatible con el artículo sexto. Por este motivo fue declarada nula también esta reglamentación, de manera que en la actualidad los ingresos de los hijos, también de los no emancipados, son gravados por separado y no conjuntamente con los ingresos de los padres. 
Distinto es, por el contrario, el caso del impuesto al capital. El tipo de gravamen no es progresivo sino proporcional: como ya dijimos asciende a un uno por ciento. Antes de aplicar el tipo de gravamen son deducidos importes exentos de veinte mil marcos por cada cónyuge y cada hijo. Por esta razón la estimación conjunta de la cuota impositiva de todos los miembros de la familia no tiene por efecto una elevación de la carga fiscal de las personas afectadas como sucede en el caso del impuesto a los réditos; antes bien, puede ser más ventajoso que los impuestos no sean deducidos del capital de cada uno de los miembros de la familia sino de la totalidad del capital de la familia. La estimación conjunta podría llegar a ser desventajosa solamente por el hecho de que cada miembro de la familia responde con su patrimonio también por los impuestos que gravan el capital de los otros miembros. Pero en este caso el legislador, ya escarmentado por lo ocurrido en el caso del impuesto a los réditos, ha establecido a tiempo una regulación con arreglo a la cual la responsabilidad del individuo puede ser reducida a un importe proporcional de la cuota impositiva total. Por esta razón no fue necesario que el Tribunal Constitucional declarara anticonstitucional la imposición de las familias en el caso del impuestro al capital.

\section{III.}

En otra causa célebre de que hubo de conocer también el Tribunal Constitucional Federal, era objeto de litigio la tributación de las sociedades mercantiles. Ya tuve ocasión antes de mencionar que en Alemania también los ingresos de las personas jurídicas están gravados con un impuesto, el cual difiere sin embargo del impuesto a los réditos de las personas naturales, configurandose como um impuesto de naturaleza especial: el impuesto a las entidades ("Körperschaftsteuer"). El cómputo de los "réditos" se efectua 
en el caso del impuesto a las entidades del mismo modo que para el impuesto a los réditos; solo que el tipo de gravamen no es progresivo sino proporcional. Además de ello todas las explotaciones mercantiles e industriales, tanto si su titular es una persona natural como si lo es una persona jurídica, están gravadas por el llamado "impuesto a los oficios o industrial" ("Gewerbesteuer"). La suma recaudada con este impuesto pasa a engrosar los ingresos de los municipios, constituyendo hoy dia su fuente más importante de financiación.

A diferencia de los impuestos a los réditos y a las entidades el impuesto industrial está construido como "impuesto de la explotación". La estimación de la cuota impositiva se hace atendiendo al importe de los "beneficios de la explotación" y al monto del "capital de explotación" afectado a la misma. A estos efectos no se entiende sin embargo por "beneficios" los obtenidos personalmente por el empresario sino los "beneficios objetivos, el producto" de la explotación; de igual manera para hacer la estimación del "capital de explotación" no es lo decisivo determinar si el capital pertenece o no al empresario o en qué medida es éste titular del mismo. Si por ejemplo el empresario para adquirir la explotación aceptó un préstamo, el pago de los intereses de este préstamo reducirán, es cierto, sus beneficios y por tanto sus "réditos", pero no los beneficios objetivos de la explotación y lo mismo puede aplicarse analógicamente al capital. La estimación de la cuota impositiva en el impuesto industrial parte, por decirlo asi, de la ficción de que toda la explotación pertenece al empresario. El municipio fija el tipo impositivo, que hoy dia asciende por término medio a aproximadamente un trece coma cinco por ciento de los beneficios de la explotación y a un cinco por mil, más o menos, del capital de la explotación.

Lo mismo que sucede en los impuestos que gravan los ingresos también en el impuesto industrial son considera- 
das las personas jurídicas, a efectos fiscales, como sujetos autónomos. Ello tiene por consecuencia, entre otras cosas, que de conformidad con las disposiciones del Derecho Civil uno de los socios de una sociedad capitalista pueda estar vinculado al mismo tiempo a la misma por un contrato de trabajo y por ejemplo ejercer las funciones de gerente de la sociedad la retribución de su trabajo, siempre que no sea desproporcionada, es reconocida como gasto de explotación y reduce por tanto la cifra de beneficios y el producto sujeto a gravamen. Hasta hace poco tiempo, sin embargo, la Ley del Impuesto Industrial establecía una excepción a esta regla para aquellos socios cuya participación en la sociedad sobrepasaba la cuarta parte de la suma total del capital. No se reconocia la posibilidad de deducir de los beneficios los sueldos percibidos por estos socios, sino que eran computados - apartándose en este punto de la Ley del Impuesto a las Entidades junto con los beneficios de la sociedad sujetos a tributación. Es decir, en este caso especial los sueldos de los socios debían ser tratados como si socios y sociedad fueran jurídicamente idénticos.

El Tribunal Constitucional tenía que decidir sobre la constitucionalidad de esta disposición concreta; para apreciarla debidamente el Tribunal utilizó como criterio el artículo tercero de la Ley Fundamental - el principio de igualdad - Como es natural igualdad no significa un tratamiento esquemáticamente igual. El Tribunal Constitucional interpreta el principio de igualdad en el sentido de que un tratamiento desigual en casos que sean semejantes en lo substancial, solo sería admisible cuando esta desigualdad se basara en una "razón objetiva." De este modo el Tribunal recaba para sí el derecho de examinar la justificación objetiva de toda ordenación legal y la fuerza persuasiva a ella inherente y el de rechazarla cuando carezca de esa fuerza de persuasión. Esto es desde luego ir demasiado lejos, pero hasta ahora ha tenido una in- 
fluencia muy beneficiosa en la actuación del Tribunal Constitucional Federal.

Para nuestro caso significaba lo siguiente: Cierto es que la Ley del Impuesto Industrial respetaba en principio la personalidad jurídica de Derecho privado, sin embargo en un caso singular, cuando la participación de un socio en el capital escedía de un veinticinco por ciento del mismo, trataba a la sociedad y al socio como jurídicamente idénticos. El Tribunal Constitucional estudió si la desviación de aquel principio estaba objetivamente justificada; después de un detenido examen llego a una conclusión negativa. La disposición en cuestión fue declarada nula.

Me he ocupado con tanta extensión de esta sentencia porque en el litigio en cuestión se apuntaba además un problema de indole general, el de las relaciones entre Derecho Fiscal y Derecho Privado. También en Alemania naturalmente se reconoce desde hace tiempo que el Derecho Fiscal es "autónomo" con relación a los demás sectores del ordenamiento jurídico. Las disposiciones del Derecho privado no pueden ser aplicadas sin más a la relación jurídica tributaria entre el Estado y el ciundadano; incluso cuando el legislador, para definir el hecho impositivo, utiliza conceptos del Derecho privado - por ejemplo, grava un "contrato de compraventa" sobre una finca estos conceptos tienen que ser interpretados muchas veces de manera distinta a la aceptada en el Derecho privado. Ya en mil novecientos veinticuatro KuRT BaLl en su escrito "Steuerrecht und Privatrecht" ("Derecho Fiscal y Derecho Privado") había hecho hincapié en esta autonomía del Derecho Fiscal. Sus tesis no tardaron en ser aceptadas por la jurisprudencia de los Tribunales y por la Ciencia. Así por ejemplo se empezó a considerar como eficaces a efectos tributarios aquellos negocios jurídicos del Derecho Privado que a pesar de ser nulos juridicamente habian producido sus efectos económicos; además, apartándose del concepto de propiedad del Derecho privado se elaboró un 
concepto "económico" de propriedad que había de valer especialmente para el Derecho Fiscal. La Ley de Adaptación Impositiva (Steueranpassungsgeset $z$ ) de mil novecientos treinta y cuatro recogió luego los principios más importantes formulados en esta jurisprudencia. Pues naturalmente también la estimación de la cuota impositiva es un procedimiento administrativo; por ello en Alemania el Derecho Fiscal es considerado como una rama especial del Derecho Administrativo (lo que, dicho sea de paso, permite no solo aplicar las conclusiones del Derecho administrativo al Derecho Fiscal, sino también a la inversa las del Derecho Fiscal al Derecho administrativo. Pero como todas las cuestiones esenciales del procedimiento en materia de Hacienda están reguladas en Alemania por una ley especial, sucede que también en muy pocos easos excepcionales recurre el Derecho Fiscal al Derecho administrativo.

A veces sin embargo se ha exagerado en Alemania el alcance de la teoría de la autonomía del Derecho Fiscal. Desde el año mil novecientos treinta aproximadamente la jurisprudencia de los Tribunales de Hacienda empezó a orientarse cada vez más por los intereses fiscales del Estado, en lugar de buscar, como exigía la misión que estaba llamada a cumplir, un compromiso razonable entre los intereses del Estado y los del ciudadano. La teoría de la autonomía del Derecho Fiscal fue utilizada sobre todo como instrumento para ampliar las obligaciones tributarias con base en la ley, derivándose de ella una interpretación bastante libre de las leyes fiscales. De este modo fueron conculcados principios esenciales del Derecho civil. Por ejemplo, conforme a los principios de nuestro Derecho mercantil la responsabilidad del socio comanditario de una "sociedad comanditaria" queda limitada al importe de su participación en la sociedad; de esta manera se trata de reducir el riesgo de esta clase de socios. Contrariando esta clara manifestación de voluntad del legislador resolvieron los Tribunales de Hacienda que el socio comandi- 
tario había de responder con todos sus bienes del pago del impuesto industrial de la sociedad. De forma análoga fueron consideradas absolutamente inexistentes en el ámbito del Derecho Fiscal algunas estipulaciones civiles concluidas con un propósito serio - así por ejemplo los contratos de trabajo entre cónyuges. De esta manera fue pervertida una teoría científica de por sí razonable y fundada.

También en este orden de cosas supuso un cambio de orientación la sentencia del Tribunal Constitucional Federal relativa al impuesto industrial. Pues esta resolución significaba a fin de cuentas que el legislador puede apartarse, ciertamente, de los principios del Derecho Civil al elaborar las leyes tributarias, pero solamente en aquellos casos em que tal apartamiento esté objetivamente justificado. De este modo se trazaben límites a una interpretación demasiado extensiva de las leyes fiscales. A raiz de dicha sentencia el legislador sometió a revisión la jurisprudencia relativa a la responsabilidad del socio comanditario; el Tribunal Constitucional calificó de anticonstitucional la negativa a reconocer los contratos de trabajo entre cónyuges. Ello ha movido luego a los Tribunales de Hacienda a reconsiderar su jurisprudencia en algunos otros sectores. Cierto es que todavía hoy existe un buen número de puntos controvertidos, pero en líneas generales puede decirse que hemos vuelto a un grado razonable de autonomia del Derecho fiscal frente al Derecho privado.

IV.

Otro tema debatido de que hubo de ocuparse en varias ocasiones el Tribunal en sus resoluciones es el problema de la dirección y control de la Economía por medio de las leyes tributarias. Todos ustedes saben que en los últimos decenios el Estado trata de influir en una medida que tiende a crecer - sobre Ia vida económica sirviéndose 
como instrumento del Derecho fiscal. Era sin embargo discutible el grado en que nuestro Derecho Constitucional admitía tal intervención en la Economía por medio de las leyes tributarias. Pues una de las notas que definem el concepto de impuesto - o al menos lo definían en un principio - es la de que tiene que ser recaudado para cubrir las necesidades financieras del Estado. Cierto es que los economistas abandonaron hace ya tiempo este criterio. Pero el jurista ha de proceder con más rigor en cuestiones de esta naturaleza y especialmente en Alemania, aunque no fuera por otro motivo que por estar regulada en la Ley Fundamental la competencia para legislar en materia fiscal de una forma que difiere en parte de la competencia para dictar las leyes destinadas a controlar la Economia, de tal manera que desde el punto de vista deI Derecho Constitucional podría llegar a ser de importancia determinar si un gravamen que persigue una finalidad dirigista en el sector económico puede calificarse todavia de "impuesto" o no.

El Tribunal Constitucional Federal tuvo que ocuparse de esta cuestión por primera vez en mil novecientos sesenta y tres. Por exigencias de la política de transportes había sido introducido por entonces un impuesto especial que gravaba la cifra de negocios de las empresas de transporte que fueran propiedad de empresas industriales. Con este impuesto se aspiraba a hacer retroceder, en beneficio de los ferrocarriles del Estado, los servicios de transporte propriedad de las empresas industriales; por tanto debía cumplir en primera línea la función de dirigir la actividad económica y solo en segundo término perseguía la obtención de ingresos para el Fisco. El Tribunal Constitucional consideró admisible que una ley tributaria persiguiera tal finalidad: solamente perdería su cualidad de auténtica ley tributaria - afirmó el Tribunal - cuando el impuesto tratara de impedir completamente la actividad sujeta al mismo, es decir, cuando la ley ya de antemano 
renunciara a obtener ingresos - o al menos ingresos substanciales. El Tribunal Constitucional Federal estimó igualmente admisible una ley por la cual, con objeto de restringir la importanción de capital, los intereses de las obligaciones de empresas alemanas quedaban sujetos también al impuesto a los rédítos cuando estuvieram en manos de un acreedor extranjero. También en este caso, en opinión del Tribunal Constitucional, era todavia compatible el objetivo de política económica de la ley con la finalidad recaudatória del impuesto. Habria que añadir que en el aspecto económico aquella medida no resultó precisamente acertada.

Por otra parte en ambas decisiones se expressa que el Tribunal Constitucional dejaría de considerar como "impuesto" un gravamen cuando éste ya no sirviera en modo alguno a la obtención de ingresos. Permítanme ustedes que ilustre esta materia con un ejemplo procedente de la jurisprudencia de los Éstados Unidos de América: Bajo Roosevelt se quería someter las empresas mineras al control del Estado; a este fin se gravó a todas las empresas con un impuesto del que sin embargo podían ser dispensadas si aceptaban determinadas reglamentaciones del Estado. El Tribunal Supremo de los Estados Unidos resolvido entonces que un gravamen de tal natureza no podia considerarse ya como "impuesto", sino que era una especie de sanción pecuniaria ("penalty"). El Tribunal Constitucional de la República Federal de Alemania no fallaria seguramente de modo diferente en un caso como éste.

En relación con las leyes fiscales dictadas con fines intervencionistas hay que tener además en cuenta - y el Tribunal Constitucional lo ha subrayado en repetidas ocasiones que solo serán admisibles, desde el punto de vista del Derecho Constitucional, cuando estén en conformidad con los principios del mismo y en especial con el principio de igualdad. Así el Tribunal declaró nula una ley por la cual se gravaba con un impuesto industrial especial a aquellas empresas comerciales minoristas que tuvieran una 
sucursal en otro término municipal. Esta disposición aspiraba a proteger a las empresas medias contra la competencia de los supermercados que se hacía cada vez más intensa. Pero el Tribunal senaló con razón que la disposición - en la forma que había sido redactada - tenía que ser también aplicada a las empresas medias que se pretendía proteger con la medida. Además de ello siguió argumentando el Tribunal — los supermercados que no tenían sucursales y por tanto operaban dentro de un solo término municipal representaban un peligro exactamente igual para sus pequeños competidores y sin embargo no se preveía la aplicación del impuesto especial a esta clase de empresas. La disposición significaba una desigualdad de trato para las empresas con sucursales, la cual carecía de justificacion objetiva atentando por ello contra el principio constitucional de igualdad. Por las mismas razones el Tribunal Constitucional declaró más tarde también anticonstitucional el impuesto con que se queria gravar las sucursales de las empresas bancarias.

Finalmente en una resolución de Diciembre de mil novecientos sesenta y seis el Tribunal Constitucional sometió a examen la constitucionalidad de todo el sistema alemán del impuesto sobre la cifra de negocios de las empresas.

El impuesto alemán sobre la cifra de negocios de las empresas es un impuesto general sobre el gasto que grava a lo largo de todas las etapas del proceso de distribución de bienes cada transmisión onerosa de mercancías y cada prestación de cualquier otra naturaleza. Hasta el fin del año pasado la cuota impositiva se estimaba aplicando un tanto por ciento fijo a la suma pagada por la prestación por lo regular un cuatro por ciento. De esta manera los productos que habían de recorrer un gran número de etapas en el proceso de producción o de distribución eran gravados en cada una de ellas con un gravamen del cuatro por ciento. A ello se añadia que todo industrial o comerciante al calcular sus precios incluía el impuesto 
suobre la cifra de negocios pagado y que estos precios servían a su vez de base para hacer la estimación del impuesto en la fase siguiente. El impuesto sobre la cifra de negocios iba por consiguiente aumentando de etapa en etapa; en Alemania se hablaba de un "impuesto alud" o de un impuesto en cascada. Con esta reglamentación resultaban muy favorecidas en el orden tributario aquellas empresas que abarcaban varias etapas del proceso de producción o distribución, es decir, las empresas "concentradas verticalmente" y perjudicadas las que solo controlaban una de dichas fases. Como las prestaciones y servicios de las empresas concentradas eran gravados en menor medida con el impuesto sobre la cifra de negocios, podían calcular precios más bajos y de esta manera ofrecer para sus productos mejores condiciones que sus competidores.

De este modo el sistema del impuesto sobre la cifra de negocios favorecia la concentración vertical. Este efecto resultaba solo en parte suavizado por medio de la institución jurídica del llamado "organicismo" ("Organschaft"). Si se cumplián determinados requisitos eran consideradas la sociedad matriz y la sociedad filial como una empresa única a efectos impositivos, de tal modo que los suministros de la sociedad matriz a la sociedad filial y viceversa no estaban sujetos al impuesto sobre la cifra de negocios. Con esta excepción se suavizaba ciertamente, con relación a las empresas integradas en un concern o holding, la desventajosa situación en que se encontraban las empresas que "controlaban una sola fase" del processo productivo; tanto más desventajosa era en cambio la posición de aquellas empresas que no pertencián a un concern.

Algunas de las empresas que se encontraban en esta situación habían interpuesto ante el Tribunal Constitucional un recurso contra esta desigualdad de trato. En su sentencia el Tribunal llegó a la conclusión de que, en efecto, el sistema jurídico alemán regulador del impuesto sobre la cifra de negocios, en la forma que les acabo de 
exponer brevemente, originaba considerables desigualdades que no podían justificarse objetivamente. Con ello sin embargo el Tribunal se hallaba ante un dilema cuya solución no había previsto la Constitución. Pues como ya dije al comienzo de mi conferencia en Alemania se considera la ley anticonstitucional como nula desde un principio; el Tribunal Constitucional Federal no hace sino constatar y declarar esta nulidad. El Derecho Constitucional no prevé la posibilidad de dejar sin efecto una ley solo para el futuro. A pesar de las dudas que abrigaba respecto a su constitucionalidad el Tribunal no pudo declarar la nulidad absoluta de la ley del Impuesto sobre la Cifra de Negocios, ya que este impuesto constituía la fuente mas importante de ingresos para la Federación. Produce anualmente de cuarenta a cincuenta mil millones de marco; más de una tercera parte del presupuesto federal es cubierta con los ingresos procedentes del impuesto sobre la cifra de negocios. Por esta razón si el Tribunal Constitucional hubiera declarado la nulidad de la ley que lo regula, se habría producido un caos financiero; las desventajas que tal decisión hubiera supuesto para la generalidad de los ciudadanos habrían sido muy superiores a los perjuicios que causaba el sistema vigente a algunos grupos, sibien importantes, de ciudadanos.

En dos casos análogos - si bien no del sector del Derecho tributario - el Tribunal había encontrado ya una salida, que en esta forma solo podia habérsele ocurrido a un jurista: en ambos casos declaró que si bien era cierto que la ley en questión no era en aquel momento todavía contraria a la Constitución, si se tenía en cuenta el curso que probablemente tomarían las cosas, en un tiempo no lejano sería con seguridad anticonstitucional. De este modo quedaba el legislador prácticamente obligado a llevar a cabo sin demora la necesaria reforma de las leyes en cuestión. En el caso del impuesto sobre la cifra de negocios no podía adoptarse esta solución, por lo que el 'Tribunal resolvió en un sentido que nuestra Constitución 
no prevé en absoluto: verdad es que en su sentencia concluye que la Ley del Impuesto sobre la Cifra de Negocios, objeto de la impugnación, infringía el principio de la igualdad, pero a pesar de ello no declara abolida la ley sino que obliga al legislador a dar cima a la mayor brevedad a la reforma del Derecho alemán regulador de dicho impuesto, reforma que se venía preparando ya desde hacía tiempo.

Entretanto ha entrado en vigor esta reforma. El impuesto grava hoy también cada una de las fases del proceso de distribución de bienes; pero el empresario está ahora autorizado a deducir de su cuota impositiva el importe del impuesto pagado en todas las fases anteriores y que hubiera sido repercutido sobre él a través del precio de la mercancía. De esta manera queda asegurado que todo bien económico al llegar al consumidor ha sido gravado en la misma proporción; ya no es posible la desigualdad de trato de las pequeñas empresas. El tipo impositivo es en la actualidad del once por ciento.

\section{V.}

Permítanme ustedes que para concluir me ocupe de un caso procedente del Derecho que regula el procedimiento de gestión tributaria:

El procedimiento para la estimación y liquidación del impuesto está regulado en Alemania por la Ley Tributaria del Reich (Reichsabgabenordnung) de trece de diciembre de mil novecientos diecinueve. En su tiempo fue ésta una ley muy avanzada; en el tiempo transcurrido diversas reformas la han complicado bastante; además de ello se ha modificado en la prática el procedimiento de gestión tributaria, sin que se haya adaptado suficientemente el Derecho que lo regula.

Con arreglo a la Ley Tributaria la piedra angular del procedimiento de gestión tributaria está constituida por la 
"estimación de la cuota impositiva". Primeramente el contribuyente presentará una declaración sobre el monto y la composición de sus ingresos, de la cifra de sus negocios, etc.. La Delegación de Hacienda competente comprobará esta declaración tributaria, consultando a este efecto si fuera necesario los libros de comercio del contribuyente; sobre la base de esta comprobación se practica y notifica la "liquidación del impuesto".

Es obvio que tal procedimiento da muchas facilidades al contribuyente para sustraerse total o parcialmente al cumplimiento de su deuda tributaria haciendo falsas indicaciones. Las posibilidades de control de que puede hacer uso la Delegación de Hacienda son reducidas. Por esta razón ya desde hace decenios, tratándose de los "grandes" impuestos a los réditos y sobre la cifra de negocios, el procedimiento es completamente distinto en la práctica. Cuando el contribuyente es un trabajador dependiente y también cuando se trata de ciertos intereses y dividendos, el impuesto a los réditos es recaudado por medio de la llamada "retención indirecta"; el patrono o el deudor de los dividendos está obligado a retener los impuestos y a ingresarlos directamente en la Caja de la Delegación de Hacienda. Cuando se trata de empresarios independientes el procedimiento de estimación de la cuota impositiva es completado con una investigación en la misma empresa.

En la actualidad al hacerse la estimación la Delegación de hacienda comprueba la declaración tributaria solo someramente y en base a la misma se acordará por de pronto la liquidación tributaria. Pero además de ello cada empresa es sometida, según un turno de varios años, a una investigación especial. Funcionarios de la Administración de Hacienda especialmente instruidos para este fin acuden a las oficinas de la empresa en questión y examinan sobre el terreno todos los libros y documentos. Los funcionarios sacan extractos de los libros de contabilidad de las empresas y los comparan con los asientos de la contabilidad de las otras empresas con las que mantienen 
relaciones de negocios. Este es un procedimiento muy eficaz; es muy difícil que a uno de estos expertos funcionarios le pase inadvertido un fraude fiscal. Muchas veces se trata solamente de que el empresario enjuicia, en el aspecto tributario, de forma diferente determinados hechos o actividades negociales y por ello los contabiliza también de un modo que difiere del que la Administración estima correcto. Ello determina que por lo regular una de estas investigaciones traiga consigo la reclamación del pago de considerables sumas en concepto de impuestos complementarios; el año mil novecientos cincuenta y uno fue posible en un solo Estado de la Federación aumentar por medio de investigaciones efectuadas en las empresas en un setenta y ocho por ciento con respecto al año anterior el importe de las sumas reclamadas en concepto de impuestos complementarios (desgraciadamente no dispongo de datos más recientes).

Sucede sin embargo que a veces la Administración va demasiado lejos en la práctica de este procedimiento, de por sí muy razonable y útil. Al investigar sociedades mercantiles algunos funcionarios han empezado a exigir últimamente ya desde que inician la investigación las actas de todas las sesiones de sus consejos directivos. En estas actas, como es natural, están consignados muchos datos que la empresa quisiera mantener secretos. En cambio para la investigación que se realiza a efectos fiscales suelen ser intranscendentes, siendo suficiente para este fin el examen de la contabilidad de la empresa. Pero la Administración podía apoyarse en una disposición - el parágrafo doscientos uno de la Ley Tributaria - que la jurisprudencia de los Tribunales de Hacienda había venido interpretando desde hacía más de treinta años como una autorización prácticamente ilimitada que se concedía a los funcionarios censores para dictar órdenes particulares de toda clase.

Ya desde mil novecientos sesenta venimos señalando que esta interpretación del parágrafo doscientos uno de la 
Ley Tributaria no puede conciliarse con nuestro Derecho Constitucional. El Tribunal Constitucional Federal ha hecho observar ya en diversas ocasiones que con arreglo a los principios de un Estado de Derecho todas las autorizaciones concedidas a la Administración debían tener un contenido concreto y delimitado. A pesar de esta crítica el Tribunal Supremo Federal de Hacienda siguió aferrado a su interpretación; sin embargo con ocasión del litigio que acabamos de referirles se vio obligado a revisar su jurisprudencia. Sí el Tribunal hubiera sancionado en su sentencia la orden de presentar las actas de las sesiones del consejo directivo, las empresas interesadas hubieran acuido con toda seguridad al Tribunal Constitucional Federal.

En Tribunal Supremo Federal de Hacienda se ha adherido ahora a İa tesis que veníamos defendiendo desde hacía años: el funcionario encargado de la investigación puede consultar los libros y los documentos de la contabilidad; solamente estará autorizado a dictar órdenes que traspasen este límite cuando tenga fundamentos cuncretos para suponer la existencia de un fraude fiscal. Por esta razón en el caso de autos no era procedente la exigencia de presentar las actas de las sesiones del consejo directivo. Esta es una solución conforme con los principios constitucionales $\mathrm{y}$ - en mi opinión — también una solución razonable. También ella la debemos (indirectamente) a los fallos del Tribunal Constitucional.

Señoras y señores: estos son algunos ejemplos del Derecho tributario alemán que pueden haberles dado ese era mi deseo - una idea de la importancia que en la actualidad tiene la jurisprudencia constitucional para nuestro Derecho tributario. También entre nosotros se discute, como es natural, si este influjo ha de valorarse positiva o negativamente. Mi opinión es que nunca podremos ponderarlo bastante. 